\title{
Cuts raise questions over future of fusion
}

Washington \& Paris. About 1,300 fusion researchers and support staff are destined to lose their jobs across the United States over the next year as fusion research enters a deep, painful and perhaps irreversible retrenchment. Despite claims elsewhere to the contrary, the cuts will inevitably cast a long shadow over global prospects for the use of fusion as a source of power.

The researchers include 260 laid off last week at the Princeton Plasma Physics Laboratory (PPPL) in New Jersey alone. They are victims of a so-called "continuing resolution" that fixes spending at a compromise rate, equivalent to around $\$ 225$ million a year for fusion against $\$ 375$ million last year, until the House of Representatives, the Senate and the Clinton administration agree a budget for the 1996 financial year, which began three weeks ago.

The cuts leave both the present and future US commitment to the International Thermonuclear Experimental

Reactor (ITER) in the balance. Without knowing what its fusion budget will be, the US Department of Energy (DoE) has been working with ITER on how United States will fulfil its commitment to its partners Russia, Europe and Japan - over the coming year on the reactor's design stage.

But this commitment is likely to be the minimum acceptable, as are any longer-term commitments to a project that many in the United States would like to see scaled-down. Although other ITER participants claim any unilateral move by the United States will not upset their own plans, a US withdrawal from the project will be a major blow.

According to sources in Congress, the US fusion budget is likely to end up close to the $\$ 229$ million proposed by the House of Representatives. There remains an outside chance, however, that it will win an extra \$56 million proposed by the Senate for PPPL (see Nature 376, 541; 1995).

At the lower level, according to Anne Davies, head of fusion at the energy department, what the United States can afford to do is not quite what ITER wants it to do. "It's a small difference," she says, "But it is going to be difficult to find it if we get the House budget."

With the main Tokamak Fusion Test Reactor (TFTR) now mothballed at Princeton, the DoE is understood to be preparing a new fusion energy plan for consideration at a meeting in November of its Fusion Energy Advisory Committee. It is expected to propose no new facilities, the closure of some existing ones, and to place the emphasis on the need for more basic research into plasma behaviour and materials.

As for ITER, its future after 1998, when the current design stage is scheduled for completion, has been questioned by a report

by a sub-panel of the Presidents' Council of Advisors on Science and Technology (PCAST). This proposed that ITER should be drastically scaled down from a cost of $\$ 10$ billion or more to just $\$ 4$ billion (see Nature 375, 713; 1995).

The PCAST panel called on the United States to seek "immediately" to renegotiate the international ITER agreement, so that

\section{IMAGE UNAVAILABLE FOR COPYRIGHT REASONS}

Where next? Scientists check the tokamak fusion reactor at Princeton, which has laid off 260 staff. the design stage could be adjusted for a smaller machine. "ITER is fine, provided that you also do research on advanced materials, advanced tokamaks and advanced steady state in parallel", says John Holdren, professor of physics at the University of California, Berkeley, and chairman of the panel. "It is crucial, even at a time of limited resources, to pursue those other lines of research."

But this proposal was roundly rejected by the ITER council in July. Robert Aymar, the director of ITER, claims there is no need to renegotiate the current agreement, and is confident that the decision to build ITER, "either alone or together", will be taken when that agreement expires in 1998.

"The United States thinks its view is the world view, but it's only the US view," says Aymar. He claims that PCAST has difficulty accepting that an international project can be more important than a domestic programme, and needs to accept the United States "is not the leader in fusion research".

If the United States decides to make its continued participation in ITER conditional on a radical reduction in size, the other part-

\section{Tritium accelerator project gets the green light}

Washington. Hazel O'Leary, the US Secretary of Energy, has formally announced her support for plans to build a proton accelerator to create tritium for US nuclear weapons, confirming earlier indications that she had rejected alternative proposals to construct a nuclear reactor for the purpose (see Nature 376, 201; 1995).

O'Leary intends to spend $\$ 280$ million over the next three years on research and development on the accelerator option, and a further \$46 million investigating the third ners will be left with a difficult choice. ITER's raison d'être as a key step towards fusion energy would be diminished. But a decision to proceed without the United States would require the other partners to reaffirm their political support for fusion, which some might be reluctant to do in the light of the US withdrawal.

Certainly ITER has little incentive at present to take up PCAST's proposal to reduce its scale. The uncertainty of the US budget process means that, even with this concession, the other ITER partners would have no guarantee of continued US participation.

Moreover, the United States seems unlikely to renege on its current commitments to ITER, which continue until 1998. John Gibbons, President Bill Clinton's science adviser, said this month in a letter to Evgeni Velikhov, the chairman of the ITER council, that "at this point" the US administration did not wish to renegotiate the existing agreement.

In the short term, Europe's commitment also appears secure. Under an agreement reached in December 1993 as part of the Fourth Framework Programme, the European Commission has promised to provide ECU200 million (US\$244 million) a year for fusion research until 1999.

But in Europe, too, doubts about medium-term prospects for fusion are not far below the surface. In particular, the European Parliament, which has long contested fusion's claims to offer cheap, safe and limitless energy, could well oppose maintaining or increasing funding for fusion after 1999, particularly after last year's nomination of Detlev Samland (Socialist, Germany), a critic of fusion research, as head of the parliament's budget committee.

Meanwhile, support for fusion research remains strong in Japan, which has limited non-nuclear resources. During the summer, Keidanren, the powerful Japanese Federation of Economic Organizations, which is made up of the chairmen of major Japanese industrial groups, called for "nationwide support" for ITER, and launched a campaign for the reactor to be sited in Japan.

Colin Macilwain \& Declan Butler

alternative, namely converting an existing nuclear power plant to produce the tritium.

The accelerator $R \& D$ programme will take place at Los Alamos National Laboratory in New Mexico, while the production accelerator will eventually be built at Savannah River, South Carolina.

Vic Reis, assistant secretary of energy with responsibility for nuclear weapons, appears to have ruled out the "dual-use" of the proposed accelerator by military and civil scientists.

C. M. 